https://helda.helsinki.fi

\title{
The Commitment to Go on Theorizing "Religion"
}

\section{Taira, Teemu}

2018

Taira , T 2018 , ' The Commitment to Go on Theorizing "Religion" ' , Method \& Theory in the Study of Religion , vol. 30 , no. 4-5 , pp. 449-462 . https://doi.org/10.1163/15700682-12341440

http://hdl.handle.net/10138/326605

https://doi.org/10.1163/15700682-12341440

acceptedVersion

Downloaded from Helda, University of Helsinki institutional repository.

This is an electronic reprint of the original article.

This reprint may differ from the original in pagination and typographic detail.

Please cite the original version. 
The Commitment to Go on Theorizing "Religion"

Full Reference: Taira, Teemu 2018. The Commitment to Go on Theorizing "Religion". Method and Theory in the Study of Religion 30(4-5): 449-462.

Abstract

There are two kinds of scholars in the world, those who do theory and those who do not. This is one of the main organizing binaries in Theory in a Time of Excess (edited by Aaron W. Hughes). All contributors of the volume agree that theory is something that is valuable. In this essay I explore what theory means in this book and how contributors to the volume highlight different aspects of theorizing. This opens up the question of who are the most fruitful conversation partners that potentially maintain and extend a commitment to theorizing.

Keywords: theory of religion, religion, discourse, religious studies

There are two kinds of scholars in the world, those who do theory and those who do not. This is one of the main organizing binaries in Theory in a Time of Excess. It is not a neutral binary, for theory is clearly seen in a more positive light. All contributors of the volume agree that theory is something that is valuable and only one contributor - Thomas J. Whitley - in his chapter hesitates whether he does theory or not. In this essay I explore what theory means in this book and how contributors to the volume highlight different aspects of theorizing. This opens up the question of who are the most fruitful conversation partners that potentially maintain and extend a commitment to theorizing. All the contributors are working in North America, so my personal input is to bring experiences from Europe into the picture. 
"Theory" and the Study of Religion

If Theory in a Time of Excess is to be believed, there are two concepts of theory in the study of religion. One is theory as an explanation of religion and the other is theory as a critical problematization of religion and scholarship. When I teach theory classes, I highlight both understandings. That is why standard theory books (e.g. Pals 2015) focusing on the former understanding of theory are only partially useful.

Another view of theory is not about explaining religion, but reflexive enquiry into categories used in making sense of things and the conditions in which knowledge production is carried out. If the standard understanding of theory is an explanation, thus giving us answers, the rationale of the second sense of theory is to "undo, through a contesting of premises and postulates, what you thought you knew" (Culler 1997: 16). Although the relationship between the two is much more complex - for instance, it is not the case that scholars who develop explanatory theories do not reflect on the nature of their categories or that approaches typically placed in the second camp would not offer answers to questions such as how power operates in society - this is a line maintained in different scholarly identifications.

The relationship between the two notions is not always congenial. To those who conceive of theory according to the first line of thinking, the second aspect is either omitted or is not considered worthy of calling theory at all (Stausberg 2009: 3, 13-14). Those focusing on the second line of thinking tend to be critical of the first. Tim Murphy, for instance, lamented more than ten years ago that the field is congratulated for producing studies utilizing an explanatory model of theory, but scholars of religion have not begun to undertake "critical interrogation of 
the very modalities of theorizing, nor of the core assumptions upon which theoretical paradigms and paradigms of theory are founded" (Murphy 2007: 14).

What made Murphy's comment possible was the fact that the second understanding of theory had already had a long life outside the study of religion. The shift from liberal humanism to "theory" is well documented (see Barry 2002). Psychoanalysis, poststructuralism, postcolonialism and other approaches placed under the heading of theory were established in Arts and Humanities. This story is by no means limited to the study of literature or any other single discipline. In fact, the story could be read by swapping literature in liberal humanism for religion in Eliadean phenomenology, although in such a reading the shift towards theory would be a late arrival.

The general discourse on theory shifted from "the commitment to theory" (Bhabha 1994: 1939) to "after theory" (Eagleton 2003), ironically, just before the publication of probably the first undergraduate introduction to key theorists (in the second sense) for students of religion, Theory for Religious Studies (Deal and Beal 2004). This work contains 29 short chapters, each introducing a theorist (two in the case of Deleuze and Guattari) and his or her implications for the study of religion. Despite the possibility of such a simple interpretation, "after theory" did not mean going back to liberal humanism (for instance, in the study of literature) or to studying religion's timeless significance in the Eliadean sense. Rather, theory became somewhat routinized; "doing theory" was no longer seen as a playground for marginal freaks who did not have enough interest in studying the real thing, i.e. the value of true literature for mankind or the essence and manifestations of religion. Furthermore, it was now considered a challenge to reexamine the life and times of theory, for instance, how intellectual life was transformed by certain theoretical discourses. 
Theory in a Time of Excess both celebrates theory and reexamines it. Furthermore, it testifies that theory in the second sense is not as routinized in the study of religion as one might want it to be. It is not difficult to share these aspirations, but I am less certain about the need to identify as someone who "does theory".

Although I remember being introduced to a colleague as someone interested in theory, I have never considered myself a theorist as such. I have rather followed Michel Foucault, who contrasted the theorist with the experimenter:

I am an experimenter, not a theorist. I call a theorist someone who constructs a general system, either deductive or analytical, and applies it to different fields in a uniform way. That isn't my case. I'm an experimenter in the sense that I write in order to change myself and in order not to think the same thing as before. (Foucault, 2001: 240.)

I also appreciate Stuart Hall's position when he suggests that "I am not interested in Theory, I am interested in going on theorizing" (Hall 1996: 150). This attitude highlights the desire to keep options open and the awareness that you may have to change your mind soon - that probably there is not a final theoretical paradigm waiting at the end of the tunnel. 
In Theory in a Time of Excess, Aaron Hughes wonders in his introduction why method and theory has become such a common phrase in the $\mathrm{CV}$, although not everyone can seriously claim to be specialists in them. It is probably because everyone should have some kind of theoretical framework in their study and it looks good to decorate one's CV with the phrase. It is meant to demonstrate that although in many positions geographical area or tradition specialists are looked for, the candidate has other skills too. Be that as it may, it is easy to recognize the problematic aspect of the trend Hughes mentions. More positively, it might be a sign of change in what is required from religion scholars.

For a long time it was common to specialize in a particular religious tradition or geographical area. This expectation is still alive and many positions are advertised with the emphasis on tradition or geographical area (Taira 2013a: 42), but an increasing number of scholars have shown that there are other ways to build one's expertise and still find a permanent position in the field. Scholars increasingly specialize in religion and popular culture, arts, media, environmental issues, and so on. I consider this a step in the right direction. However, even then there is an expectation that theory is something that comes on top of that, rather than being a primary guide for choosing empirical areas of expertise. This is noted by Jonathan Z. Smith, who writes that with the exception of Melford Spiro, "I can think of no one in contemporary religious studies who states that they chose their particular area of study to solve an issue in the general theoretical construction of religion" (Smith 2013: 72).

Many of my students are inclined to think that there is something dubious if the interest in a certain research topic is driven by theory. I try to make them see that it can be a good starting point. For instance, I have never been particularly interested in Druidry and I have never claimed to know much about its history. However, the fact that the Druid Network was 
granted a charitable status in England and Wales gave me an opportunity to apply and test certain theoretical ideas to the case. With the help of my colleague, Suzanne Owen, who knows much more about Druidry in Britain than I do and who shares enough of the theoretical terrain, I was able to carry out research about the case. However, it did not make me an expert in Druidry. (Owen \& Taira 2015.)

My interest in writing about Finnish Wiccans, who tried to attain the status of a registered religious community, was similar (Taira 2010). Studying the case included a lot of reading about Finnish Wiccans, convincing me that I was able to carry out the research, but it would have been silly to call myself an expert on Wicca or Paganism. Of course, this did not prevent others from sending me requests to write about Paganism in Finland. Some years ago I turned down the query to write about Wiccans in Finland for two reasons. First, having written about the registration process that took place in 1999-2001 hardly made me an expert on Finnish Wiccans in the 2010s. I would have needed time to update my knowledge of the field and at that point I did not have the time. Second, I have never been seriously intrigued by Wiccans as such. My interest was theoretically focused on the category of religion in the registration process and Wiccans simply happened to be a suitable example.

The above-mentioned empirical case studies have served "as exempli gratia of some fundamental issue in the imagination of religion" (Smith 1982: xi), rather than a demonstrated specialism tied to a particular group or tradition. They testify how theory-driven research settings are possible and valuable. They are not about marginal groups as such; they highlight how the category of religion operates as part of social practices (see also Taira 2013b). 
The Limits of Theory?

The first set of papers in Theory in a Time of Excess explores whether theory has restraints posed by the data. More generally, I read them as asking what scholars of religion need most a push towards theorizing or toeholds that limit theorizing? Jason Blum argues that there are indeed restraints to theory posed by data, in a sense that theorizing cannot ignore the consciousness of agents if theorizing is to have any relevant connection to data. Blum is clear that he does not identify with Wilfred Cantwell Smith's position that "statements about a religion must be acknowledged by that religion's adherents in order to be regarded as valid" (54). Furthermore, in highlighting theory as explanation he is convincing in suggesting that there is no need to strive for a comprehensive theory of religion. It remains debatable what he means by suggesting that the deconstructive critique of "religion" is not an end in itself - this was a topic of intensive social media debate in 2016 that began from my interview (Taira 2016) - but I suspect we disagree on this. However, I want to pay attention to his main message about restraining theory, and it prompts me to highlight Richard Rorty's suggestion that it is needless to assume that "somebody's own vocabulary is always the best vocabulary for understanding what he is doing, that his own explanation of what's going on is the one we want" (Rorty 1982: 200, emphasis original). Rorty continues that the only rule is that "it's always wise to ask what the subject thinks it's up to before formulating our own hypotheses. But this is an effort at saving time, not a search for the 'true meaning' of the behavior" (Rorty 1982: 200, emphasis original). I do not think that other restraints are needed. It is up to peers to decide whether one's theorizing resonates with theirs and whether the justification one gives is plausible.

The issue is not necessarily about whether Blum is right or wrong in his main point. It is more important to notice that of all the possibilities of selecting a perspective, he has chosen to warn 
that theory may go too far and become detached from the data. Which one is more important: to remind students and scholars that data or real world restrains their theorizing or that they need explicit theorizing to construct their object of study and explore it on the basis of a selected framework? Blum has chosen the former. I would prefer to highlight the latter, as I do not think that our field as a whole is anywhere close to having an overemphasis on theorizing. It would require a lot of effort to convince me that this is the difference between North America and Europe.

Who are our conversation partners?

The main contribution in the second section is written by Merinda Simmons, who raises doubts about the relevance of traditional religious studies' conversation partners. She suggests that it might be wise not to worry too much about the AAR and not to go back-and-forth between theory (good) and theology (bad). Her standpoint is particularly understandable as her route to religious studies was through literary theory. Despite the obvious differences - we studied in different continent and I have always been institutionally in the study of religion - her piece resonates with my experience.

First of all, when I started my doctoral studies I had doubts whether the study of religion was the most suitable institutional location. It was a set of studies - by Jeremy Carrette, Timothy Fitzgerald, Gavin Flood, Richard King, Russell T. McCutcheon and others - published in the late 1990 s and early 2000 s that gave me confidence to stay in the study of religion. Before that I had troubles in combining my major to my interest in "theory" (in the second sense), but they 
spoke the language I was socialized to speak when studying cultural history, communication and philosophy in addition to the study of religion.

Secondly, it has not always been clear to me why scholars of religion spend so much time "cataloguing all the ways in which theologians get it wrong" (Simmons p. 64) and worrying about the problems some organizations and journals have (think about the AAR and JAAR). I tend to follow my desire to contribute to those organizations, journals, conferences and book series that share my interests, while paying some attention to other players inside and outside of academia every now and then to avoid insularity. Because there are struggles over resources and recognition, it would be unwise to ignore them totally. Theoretically, however, there are more relevant conversation partners with whom to develop ideas further. As Simmons suggests, not talking to one group does not mean not talking to any group. It is wise to interact with the most productive conversation partners. However, situations and perspectives change. Now that I am working in a faculty of theology after spending years in a university with no theology department, some of these debates have become more actual than they used to be. For instance, I have found myself thinking about the study of religion's relation to inter-religious discourses in a way I did not find necessary previously. Suddenly it is relevant to emphasize that my idea of the study of religion differs from, say, Martin Forward's, who in his Inter-Religious Dialogue suggests that in religious studies "we attempt to understand and appreciate other [than our own] ways of responding to the mystery of Transcendent grace that surpasses, but does not bypass, human insight and intellect" (Forward 2001: 3). Although the science versus theology debate is not the most interesting game for me - it is more useful to ask whether "religion" is an appropriate category at all for scholarly purposes, how it is separated from the (non-religious) secular and what functions such categories have in society - sometimes we end up playing a round of the old game. 
To sum up: there are two games to play inside academia. First is the one in which scholars of religion try to improve the resources they have and the conditions they work in. This is why the profile of the AAR matters for North American scholars of religion. This is also why the 2017 statement by the EASR (European Association for the Study of Religions) against the recentlyfounded European Academy of Religion matters, as the EASR saw the latter pursuing a normative theology and inter-religious dialogue as well as being an initiative intent on displacing the existing organization. ${ }^{1}$ The second game is where a lot is shared but the tiny differences are highlighted. It is where some of the allies in the first turn into adversaries and where the theory vs. theology debate loses its urgency. I shall take a couple of examples in which the category of "religion" is my center of attention.

If I reflect on the European trends I would suggest that two intersecting sets of approaches are considered fashionable. One is lived religion and another is new materialism, both referred to in the volume. Both have their strengths, but, as Aaron Hughes notes, the term "religion" is not seriously queried in them. The lived religion approach makes sense among historians and sociologists of religion. It was an argument against traditional history that concentrated on elites and specialists; it was also targeted against traditional sociology of religion that paid attention to religious institutions. It was not much of a novelty for someone (like me) who studied in

\footnotetext{
${ }^{1}$ The European Association for the Study of Religions (EASR) has been the main European association in the field of study of religion since its foundation in 2000. Then, founded in 2016, the European Academy of Religion (EuARe) presented itself as the network of networks concerning religion. The EASR stated that the creation of such an association was "superfluous" and it represented "an objectionable disregard for the existing organizational structures in the field." As I see it, despite the diversity within both, the EASR represents people working primarily in the field/discipline of the study of religion, while EuARe is dominated by theologians (not limited to Christian theology), including those concerned with interfaith or inter-religious dialogue. For the EASR statement, see http://easr.org/fileadmin/user_upload/content/pdfs/EASRIAHR_joint_statement_about_the_EuARe.pdf
} 
Finland, because studying everyday practices by ethnographic means was the preferred way of doing research in my department. Because of that background, lived religion was simply a new branding of a familiar approach that did not see institutionalized doctrines and sacred scriptures as the primary locus of religiosity. It supported the idea that everyday practices of ordinary people provide more interesting material for theorizing religion. The problem for me was that lived religion scholars were too relaxed to talk about religion without ever really questioning the reproduction of the discourse on religion. The debate concerning "religion" is acknowledged, but it has not changed anything substantial in lived religion scholarship.

A good example of the relative success of lived religion discourse is its spread outside the study of religion. For example, political scientist Elizabeth Shakman Hurd (2015) argues convincingly that the category of religion is a highly problematic concept for international law and international public policy and that it is better to drop the concept from such discourses, while writing about lived religion without any problematizing.

The so-called material turn in the study of religion is not much different. First of all, the term is fuzzy as it covers different approaches, ranging from the role of material items in religion to studies on how material items mediate transcendence and sustain beliefs about transcendent beings, to studies promoting "new materialist" theorizing in the study of religion (e.g. Schaefer 2015; Vasquez 2011). I have felt ambiguous about the new materialism. The brightest proponents of such approaches have introduced and applied relevant theoretical debates to the study of religion. It is not too far from where I come from. After all, my first edited volume was about Gilles Deleuze - one of the key philosophers behind contemporary new materialism discourse - and I have written about the fruitfulness of the concept of affect in cultural studies, particularly as it has been applied in the work of Lawrence Grossberg. Given this background, 
I find recent attempts to introduce "new materialism" to theoretical repertoire in the study of religion interesting, to say the least. However, the difference becomes obvious when "religion" is theorized.

Manuel A. Vásquez (2011: 325-326) acknowledges the critiques of the category of religion in his More Than Belief: A Materialist Theory of Religion, but he has no problem in writing about religious experience, religious phenomena, and so on. There are moments of brilliant theorizing in his study, but surprisingly little reflection about the problems related to the category of religion. This indifference is explicit in his response to papers reviewing his study. He writes that he "purposely avoided getting entangled in debates about what is religion" (Vásquez 2012: 660), and even when offered an opportunity to clarify he judges that these debates "have run their course" (660) as if one could continue neglecting discursive studies related to the category of religion and go on studying religion in a materialistic framework without defining religion or addressing what - if anything - is its specificity.

Donovan A. Schaefer's Religious Affects (2015) is no different. While his attempt to introduce the concept of affect to our theoretical toolbox is admirable, it is confusing when he writes about "religious bodies" (14) and how "religion flows over the boundaries of language or thought" (10). The overall issue can be exemplified by referring to his claim that chimpanzee dance is religious. Schaefer suggests that if we wish to understand animals - chimpanzee dance, for instance - we must think that religion is not a uniquely human property (3). It is obvious to me that the boundary between animals and humans is problematic. However, Schaefer's idea about animal religion is not convincingly constructed or particularly helpful. To clarify this, I shall follow Deleuze and Guattari's (1998) three-fold classification between the inorganic stratum (matter), the organic stratum (life) and the alloplastic stratum (culture) (see Holland 
2013: 22-28). The line between the organic and the alloplastic stratum is not the same as between animals and humans, because some animals - Deleuze and Guattari (1998: 310-350) use birds, such as Australian grass finches, as an example - have expressive, symbolic qualities too. However, it does not follow from this that we should call such activities religious. It would require definition and theory of what distinguishes religion from other expressive, alloplastic activities such as art or culture. This is not what Schaefer offers. Perhaps it is for this reason that he writes at the end of the study, that "Why do some dances get called religion and not others? The animal religion approach does not answer this question" (Schaefer 2015: 213). We both agree. The difference is that I find it problematic that the question remains unanswered; he doesn't.

Conversations to be developed: cognitive science and pragmatism

The third section of the volume begins with Claire White's balanced introduction to the cognitive science of religion (CSR). CSR represents an example of theory in the explanatory sense. That is why the chapter is different from most contributions. It is not entirely clear why CSR is included as the only such example, but at least it has been one of the visible forces in maintaining theoretical debates in the study of religion for almost three decades.

White defines her target audience as those new to CSR. I do not consider myself part of her target audience as I had the opportunity to listen to Pascal Boyer, Stewart Guthrie and E. Thomas Lawson as an MA student twenty years ago in Finland and learn about CSR from my colleagues Veikko Anttonen and Ilkka Pyysiäinen, among others. It is perhaps for this reason that White's writing, though an up-to-date introduction to the field, brings feelings of déjà vu. 
I have sometimes mentioned to my students that the evangelizing tendencies in promoting CSR have become more moderate since the late 1990s and early 2000s, but White's contribution echoes the past, although she does not fall into hyperbole. The way in which CSR has been communicated has had its problematic moments. Therefore, White's claim that doubts concerning CSR have taken place because it happens to all new kids in town is unhelpful. Take D. Jason Slone's Theological Incorrectness (2004) as an example. According to Slone, "socioculturalist scholars of religion produce scholarship that turns out to be little more than journalism" (43), "postmodernists" emphasize that "all ideas are to be respected as equally valid" (42), "What is true, and this is another postmodernist paradox, is whatever is in fashion" (44). CSR, on the contrary, "truly represents a revolution in the study of human behavior" (45). If this is how one wishes to implement one's favorite approach to the field, it should not come as a surprise that some may be less than interested in cooperating and building bridges.

Rather than reading dismissive accounts about other approaches, I would like to see CSR scholars demarcate in their programmatic statements what CSR cannot explain - which questions that are relevant for the study of religion as a whole have to be left to other approaches? For instance, one of the questions I have been curious to investigate is why, given the obvious similarities between social structures, is atheism markedly less popular in Finland than in Sweden. I would be surprised to find one day CSR having much to say about this. Instead, it is more appropriate to study the national histories of the two countries. The cognitive approach is relevant for other purposes.

It is not that CSR scholars have not problematized what counts as religion for them, but Matt Sheedy is correct in commenting that CSR largely bypasses social constructionist critique of the category of religion. White replies that paying attention to the historical lexicon of religion 
is not relevant for CSR. In one sense, she is right; many CSR research designs do not need it. However, the issue is of great significance for many scholars. If White's comment is taken seriously, it seems that there is not going to be much attention paid by CSR scholars to those who are interested in studying religion-related discourses. Why, then, would CSR scholars expect others to pay more attention to their findings?

The final section shifts the theoretical discussion elsewhere. It begins with Matthew Bagger's proposition not to impose a single theoretical approach to the study of religion. This idea is already mentioned by Jason Blum in his contribution, but Bagger extends it by arguing that religious studies is a field, not a discipline, before introducing Robert Brandom's pragmatism to the study of religion. I have no problem with the idea of theoretical pluralism or eclecticism as proposed by Bagger. In fact, I have used Isaiah Berlin's metaphor of scholars as foxes (as opposed to hedgehogs) that Bagger refers to in his contribution. Furthermore, I can see value in the field/discipline debate in thinking about the self-image of scholars of religion, but I struggle to find much urgency in the topic. I am not aware of any department whose fate has depended on this issue, so I shall direct my comment elsewhere. Namely, in an endnote Bagger mentions that he follows the line of argument developed by Richard Rorty in his "Cultural Politics and the Question of the Existence of God". Despite this, Bagger deals solely with Brandom, but for my purposes Rorty is more useful and his piece is an easily digestible example of antirepresentationalism. Rorty suggests that the ontological question about the existence of God is fruitfully analyzed as the question of the cultural desirability of God-talk (Rorty 2007: 24), thus offering one potential framework to theorize beliefs as discursive moves outside the true/false binary. According to Rorty (2007: 8-9), attempts to appeal to authorities superior to society are moves in the game of cultural politics and from that point of view, what is said in the name of God - or what is referred to as "religion" in public discourse - is said in the name 
of some interest group. Furthermore, it argues, pace CSR, that what makes statements effective and salient is mainly related to previous expectations maintained by various interest groups rather than formal qualities related to their memorability:

If I say that round squares are [...] possible, because I have in fact recently encountered several such squares, nobody takes me seriously. The same goes if I come out of the forest claiming to have spotted a unicorn. [...] If I explain to a Christian audience that personal observation has shown me that God is, contrary to popular opinion, female, that audience will probably just laugh. But if I say that I have seen the Risen Christ in the disk of the sun on Easter morning, it is possible that I shall be viewed with respect and envy. [...] In short, God-reports have to live up to previous expectations. (Rorty 2007: 10.)

This quote puts the two sections, particularly the chapters by Bagger and White, potentially into conversation, though this did not fully take place in the volume. I also believe that Rorty's views about seeing statements about supernatural entities as social practices rather than as religious beliefs that may or may not be explained by reference to cognitive mechanisms might provide a hint to Brad Stoddard's question of why CSR has been quite well funded by the Templeton Foundation. Or, rather, why projects that theorize statements (about supernatural entities, to have a religion and so on) as social practices might be less fundable by foundations that utilize science vs. religion discourse where the truth of propositions is a central issue.

Theory in a Time of Excess offers a variety of viewpoints and perspectives about the significance of theorizing in the study of religion. While authors seem to have little in common when it comes to nuances, the volume as a whole demonstrates the liveliness of debates 
revolving around "theory" (particularly in the second sense, not simply as synonymous to explanation) and the category of "religion". More generally, it shows how flexible scholars can be when responding to papers written from different, sometimes quite unfamiliar, theoretical standpoints. Although the volume is written by North American scholars and it echoes some local anxieties and trends, it speaks quite well to European scholars too. My contribution here has selectively highlighted some points that could carry the debate further, but I shall leave the usefulness of the suggested direction for others to evaluate. However, the commitment to "go on theorizing" - becoming skilled and self-reflective about the tools we use and the conditions in which we use them - remains a guideline I attempt to convey in my writing and teaching. Although many students come to such method and theory courses with the expectation that it is going to be boring, surprisingly many say that it helps them to revitalize their motivation to continue with their studies. That gives me hope and it shall be my pinch of optimism for fellow scholars who intend to keep on theorizing.

\section{References}

Barry, Peter (2002). Beginning Theory. Manchester: Manchester University Press.

Bhabha, Homi K. (1994). The Location of Culture. London: Routledge.

Culler, Jonathan (1997). Literary Theory. Oxford: Oxford University Press. 
Deal, William E. \& Timothy K. Beal (2004). Theory for Religious Studies. New York: Routledge.

Deleuze, Gilles and Félix Guattari (1998). A Thousand Plateaus: Capitalism and Schizophrenia. Minneapolis: Minnesota University Press.

Eagleton, Terry (2003). After Theory. London: Allen Lane.

Forward, Martin (2001). Inter-Religious Dialogue: A Short Introduction. Oxford: OneWorld.

Foucault, Michel (2001). Power: Essential Works of Foucault 1954-1984 Volume Three. London: Allen Lane.

Hall, Stuart 1996. On Postmodernism and Articulation: An Interview with Stuart Hall. Edited by Lawrence Grossberg. In David Morley \& Kuan-Hsing. Chen (eds), Stuart Hall: Critical Dialogues in Cultural Studies. London: Routledge, 131-150.

Holland, Eugene W. (2013). Deleuze and Guattari's A Thousand Plateaus. London: Bloomsbury.

Hurd, Elizabeth Shakman (2015). Beyond Religious Freedom: The New Global Politics of Religion. Princeton: Princeton University Press.

Murphy, Tim (2007). Representing Religion: Essays in History, Theory and Crisis. London: Equinox. 
Owen, Suzanne \& Teemu Taira (2015). The Category of 'Religion' in Public Classification: Charity Registration of the Druid Network in England and Wales. In Trevor Stack, Naomi Goldenberg \& Timothy Fitzgerald (eds), Religion as a Category of Governance and Sovereignty. Leiden: Brill, 90-114.

Pals, Daniel L. (2015). Nine Theories of Religion. Oxford: Oxford University Press.

Rorty, Richard (1982). Consequences of Pragmatism: Essays 1972-1980. Minneapolis: University of Minnesota Press.

Rorty, Richard (2007). Philosophy as Cultural Politics: Philosophical Papers, Volume 4. Cambridge: Cambridge University Press.

Schaefer, Donovan E. (2015). Religious Affects: Animality, Evolution, and Power. Durham: Duke University Press.

Slone, D. Jason. (2004). Theological Incorrectness: Why Religious People Believe What They Shouldn't. Oxford: Oxford University Press.

Smith, Jonathan Z. (1982). Imagining Religion: From Babylon to Jonestown. Chicago: The University of Chicago Press.

Smith, Jonathan Z. (2013). On Teaching Religion. Oxford: Oxford University Press. 
Stausberg, Michael (2009). There is Life in the Old Dog Yet: An Introduction to Contemporary Theories of Religion. Michael Stausberg (ed.), Contemporary Theories of Religion: A Critical Companion. London: Routledge, 1-21.

Taira, Teemu (2010). Religion as a Discursive Technique: The Politics of Classifying Wicca. Journal of Contemporary Religion 25(3): 379-394.

Taira, Teemu (2013a). Making Space for Discursive Study in Religious Studies. Religion 43 (1): $26-45$.

Taira, Teemu (2013b). The Category of 'Invented Religion': A New Opportunity for Studying Discourses on 'Religion'. Culture and Religion 14(4): 477-493.

Taira, Teemu (2016). Categorising "Religion": From Case Studies to Methodology. Religious Studies Project, 19 September 2016.

http://www.religiousstudiesproject.com/podcast/categorising-religion-from-case-studies-tomethodology/

Vásquez, Manuel A. (2011). More than Belief: A Materialist Theory of Religion. Oxford: Oxford University Press.

Vásquez, Manuel A. (2012). On the Value of Genealogy, Materiality, and Networks: A Response. Religion 42(4): 649-670. 